\title{
Space Acquired Photography
}

Interested in a photograph of the first space walk by an American astronaut, or the first photograph from space of a solar eclipse? Or maybe your interest is in a specific geologic, oceanic, or meteorological phenomenon? The U.S. Geological Survey (USGS) Earth Resources Observation and Science (EROS) Center is making photographs of the Earth taken from space available for search, download, and ordering. These photographs were taken by Gemini mission astronauts with handheld cameras or by the Large Format Camera (LFC) that flew on space shuttle Challenger in October 1984. Space photographs are distributed by EROS only as high-resolution scanned or medium-resolution digitized products.

Project Gemini photographs were taken by NASA astronauts with handheld cameras during Gemini Missions III through XII between March 23, 1965, and November 15, 1966. The collection includes over 2,500 camera images of geologic, oceanic, and meteorological targets, as well as historical photography, such as the first docking of two space vehicles. The Gemini photography collection was shot on 70-mm and 5 inch by 5 inch film, primarily color, but with some black and white and color-infrared coverage. The USGS also provides search aids and product support through their commercial vendors (http://edc2.usgs.gov/referrals/index.asp).

The Gateway to Astronaut Photography of Earth (NASA-Johnson Space Center) hosts the complete collection of astronaut photographs of the Earth and is located at http://eol.jsc.nasa.gov/.

Shuttle LFC images were acquired during the space shuttle Challenger flight on October 5-13, 1984. The LFC was mounted in the cargo bay and operated by signals transmitted
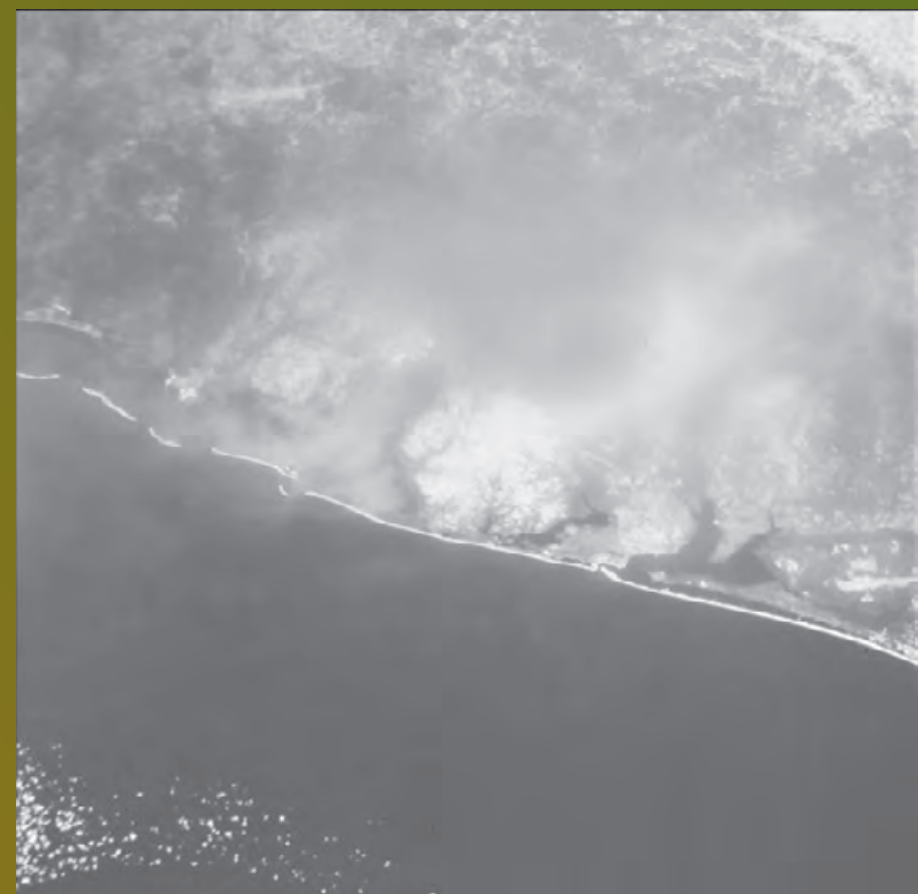

Gulf Coast of the United States, including the area of Mobile, Alabama, and Pensacola, Florida. Entity ID: AR7G05000445609; Center Coordinates: 30²2'53"N, 878'35"W; Acquisition Date: 1965/08/24

from ground controllers. Shuttle LFC photographs are distributed as digital products only.

\begin{tabular}{|c|c|c|c|}
\hline Gemini manned flight & Date & Astronauts & Duration \\
\hline Gemini III & March 23, 1965 & Virgil I. Grissom, John W. Young & 4 hours 52 minutes 31 seconds \\
\hline Gemini IV & June $3-7,1965$ & James A. McDivitt, Edward H. White II & 4 days 1 hour 56 minutes 12 seconds \\
\hline Gemini V & August 21-29, 1965 & L. Gordon Cooper, Jr., Charles Conrad, Jr. & 7 days 22 hours 55 minutes 14 seconds \\
\hline Gemini VII & December 4-18, 1965 & Frank Borman, James A. Lovell, Jr. & 13 days 18 hours 35 minutes 1 second \\
\hline Gemini VI & December $15-16,1965$ & Walter M. Schirra, Jr., Thomas P. Stafford & 1 day 1 hour 51 minutes 24 seconds \\
\hline Gemini VIII & March 16, 1966 & Neil A. Armstrong, David R. Scott & 10 hours 41 minutes 26 seconds \\
\hline Gemini IX & June $3-6,1966$ & Thomas P. Stafford, Eugene A. Cernan & 3 days 21 hours \\
\hline Gemini X & July $18-21,1966$ & John W. Young, Michael Collins & 2 days 22 hours 46 minutes 39 seconds \\
\hline Gemini XI & September $12-15,1966$ & Charles Conrad, Jr., Richard F. Gordon, Jr. & 2 days 23 hours 17 minutes 8 seconds \\
\hline Gemini XII & November $11-15,1966$ & James A. Lovell, Jr., Edwin E. Aldrin, Jr. & 3 days 22 hours 34 minutes 31 seconds \\
\hline
\end{tabular}

http://science.ksc.nasa.gov/history/gemini/gemini.html 


\begin{tabular}{|c|c|c|c|c|}
\hline Digital file sizes & Original film size & Spot size & \multicolumn{2}{|c|}{ File sizes } \\
\hline \multirow{5}{*}{ Gemini } & \multirow{3}{*}{$70 \mathrm{~mm}$} & & Black and white & Color/color infrared \\
\hline & & 21 micron (1200 dpi) & $15 \mathrm{MB}$ & $45 \mathrm{MB}$ \\
\hline & & 14 micron (1800 dpi) & $30 \mathrm{MB}$ & $90 \mathrm{MB}$ \\
\hline & \multirow[t]{2}{*}{$5 \times 5$ inch } & 21 micron (1200 dpi) & $40 \mathrm{MB}$ & $120 \mathrm{MB}$ \\
\hline & & 14 micron (1800 dpi) & $80 \mathrm{MB}$ & $240 \mathrm{MB}$ \\
\hline \multirow[t]{2}{*}{ Large Format Camera } & \multirow[t]{2}{*}{$9 \times 18$ inch } & 21 micron (1200 dpi) & 117 MB (x 2 files) & $350 \mathrm{MB}$ (x 2 files) \\
\hline & & 14 micron (1800 dpi) & 262 MB (x 2 files) & 787 MB (x 2 files) \\
\hline
\end{tabular}

Actual file sizes may differ from those listed in the table above. Metadata printed on the film are scanned along with the image data, and a USGS visual identifier is embedded in the image.

\section{High-Resolution and Medium-Resolution Digitized Photography}

Both Gemini and LFC film products have been scanned and are now available as either high-resolution scanned or medium-resolution digitized photography. Medium-resolution photography is digitized at approximately $400 \mathrm{dpi}$, and files are created in TIFF format. The file size for medium resolution products is approximately $15 \mathrm{MB}$ for black and white images and $40 \mathrm{MB}$ for color images. High-resolution images can be $105 \mathrm{MB}$ per black and white image and as much as $240 \mathrm{MB}$ for a color image.

\section{Prices}

High resolution scanned: $\$ 30.00$ per frame*

Medium resolution digitized: $\$ 3.00$ per frame*

*Prices subject to change.

For current delivery options see

http://eros.usgs.gov/products/aerial/space.html

\section{Search and Order}

All the images at EROS can be searched and ordered through Earth Explorer at http://earthexplorer.usgs.gov

\section{Data Applications}

Gemini images were taken as long ago as the mid-1960s, before Landsat was launched, and cover many areas outside the United States for which 1960s aerial photography is not available.

The LFC imager involved only one flight mission in October of 1984. The LFC was retired from service after the loss of the space shuttle Challenger.

The Gemini and LFC imagery is useful for making general land cover assessments and for general studies of change in geomorphic features (for example, barrier islands) and hydrology (for example, wetlands/lakes).

\section{For further assistance, please contact:}

Customer Services

U.S. Geological Survey

Earth Resources Observation and Science (EROS) Center Sioux Falls, SD 57198-0001

Fax:

Email: 605-594-6589

Business hours: lta@usgs.gov Monday through Friday 8 a.m. to 4 p.m., Central Time 